\title{
A bibliometric analysis of research on rice and irrigation from the 'Agronomy' category based on the Web of Science
}

\author{
Jie Sun and Bao-Zhong Yuan*
}

\begin{abstract}
A bibliometric analysis was performed on a total of 1319 articles and reviews on rice and irrigation from the 'Agronomy' category based on the Web of Science (WoS) during the period 1965-2018. The results showed that the number of publications had grown rapidly over the past years, and English was the dominating language (96.437\%). The top five most productive authors were E. Humphreys (Philippines), B. A. M. Bouman (Philippines), S. Fukai (Australia), J. Z. Xu (China) and A. Kumar (India). There were 98 core journals involved in publication; Agricultural Water Management was the most productive journal with 273 articles (20.697\%), followed by Field Crops Research (176; $13.343 \%)$ and Paddy and Water Environment (162; 12.282\%), each with more than 150 papers. India was the most productive country with 313 articles (23.73\%), followed by China (218, 16.53\%), USA (163, 12.36\%), Philippines (154, 11.68\%), Japan (152, 11.52\%) and Australia (121, 9.17\%). Among the institutions working on rice and irrigation, the top 3 were International Rice Research Institute, Philippines, Punjab Agricultural University, Pakistan and Chinese Academy of Sciences, China. Among 13 ESI top papers, there was one hot paper and four review papers.
\end{abstract}

Keywords: Agronomy, bibliometric analysis, irrigation, rice research.

As the global population continues to steadily increase, staple crop yields must also increase to meet the demand for food ${ }^{1}$. Rice (Oryza sativa L.) is the staple food for more than half of the global population. It is the main staple in tropical Latin America, and East, South and Southeast $\mathrm{Asia}^{2}$. The rice cropping systems are of global importance in terms of food security ${ }^{3}$. Increasing water scarcity threatens the sustainability of rice production ${ }^{4}$. The conventional system for irrigating rice is to flood and maintain free water in the field. Initial flooding provides favourable conditions for land preparation and rapid crop establishment through transplanting and efficient weed management. However, the conventional system uses a large amount of water because of high water loss through evaporation, seepage and percolation. A challenge for sustainable rice production is to decrease the amount of water use and maintain or increase yield through improved water use efficiency ${ }^{5}$.

The system of rice intensification (SRI) is an agroecological approach to rice cultivation that seeks to create optimal conditions for healthy plant growth by minimiz-

Jie Sun is in the Library and Bao-Zhong Yuan is in the College of Plant Science and Technology, Huazhong Agricultural University, Wuhan City, Hubei Province, PR China, 430070.

*For correspondence. (e-mail: yuanbz@mail.hzau.edu.cn) ing inter-plant competition, transplanting widely spaced young single seedlings, and optimizing favourable soil conditions with organic amendments, increased soil aeration by weeding and controlled water management. It is also an agricultural system consistent with sustainable agriculture as well as conservative agriculture contributing in the preservation of natural resources like water and land, and reducing chemicals applied to crops and environmental pollution ${ }^{6-9}$. These systems include saturated soil culture, aerobic rice ${ }^{10}$, alternate wetting and drying $^{4,11-13}$, and drip and sprinkler irrigation. The breeding target is a high yield potential under irrigation, an acceptable grain quality and water consumption reduced by about $50 \%$ compared with paddy rice. In a water-limited environment, a higher level of drought resistance and reduced yield loss by drought stress are required ${ }^{14}$. Currently, dry seeded rice (DSR) is gaining popularity among farmers in Central China because of reduced irrigation requirement and cost for crop establishment, and conduciveness to mechanization ${ }^{15}$.

In recent years, bibliometrics has been broadly used as a quantitative method of analysis in many scientific research fields, such as water use efficiency in agriculture $^{16}$, planthoppers ${ }^{17}$, rice physiology and management in China ${ }^{18}$, water footprint research ${ }^{19}$, wastewater irriga$\operatorname{tion}^{20}$, biomass energy and environment ${ }^{21}$. In this study, a 
Table 1. Document type distribution for irrigation on rice research

\begin{tabular}{lccccc}
\hline Document type & Records & Ratio of 1319 (\%) & Citations & Average citation & $h$-index \\
\hline Article & 1265 & 95.906 & 20,726 & 16.38 & 64 \\
Review & 54 & 4.094 & 2,333 & 43.2 & 22 \\
Proceedings paper & 35 & 2.654 & 1,273 & 36.37 & 16 \\
Book chapter & 11 & 0.834 & 750 & 68.18 & 7 \\
\hline
\end{tabular}

bibliometric analysis of 1319 articles reported in the Web of Science (WoS) Core Collection were searched using the keywords 'irrigation' and 'rice', during 1900 to 2018 (up to 5 December 2018). Global scientific research on rice with irrigation is analysed from subject category, journal, country/region, institution and author. And the hotspots were analysed in high-quality journals.

\section{Methodology}

\section{Web of Science}

The publication counts from the WoS Core Collection were derived from the following databases: The Science Citation Index-Expanded (SCIE), 1900-present; Social Science Citation Index (SSCI), 2005-present; Conference Proceeding Citation Index-Science (CPCI-S), 2015present; Conference Proceeding Citation Index-Social Sciences and Humanities (CPCI-SSH), 2015-present; Current Chemical Reactions (CCR-EXPANDED), 1986present, and Index Chemicus (IC), 1993-present.

\section{Data collection}

The study surveyed papers in the SCIE database published from January 1900 to July 2018 (retrieval data last updated: 5 December 2018). We used the keywords 'rice' and 'irrigation' to search the database, with the query $\mathrm{TI}=$ (rice and irrigation), in terms of topic to retrieve bibliographic records. The document types used were articles and reviews, further refined by WoS category 'Agronomy'.

\section{Data analysis}

The selected publications were further analysed with respect to language, document type, country and citations, main journals, journal category and impact factor (IF) using Microsoft Excel 2010 with functions. The contributions of different countries and institutions were estimated by affiliation of at least one author of the published papers. The number of citations has been widely accepted as an indicator of impact of paper. IFs were taken from the Journal Citation Report (JCR) published in 2018 .

\section{Results and discussion}

\section{Document type and language}

The 1319 publications were identified in SCIE between 1965 and 2018. The document types were articles and reviews (Table 1). The article was the dominant document type comprising $95.906 \%$ (1265 of the total 1319), the remaining publications were reviews $(54,4.094 \%)$, proceeding papers $(35,2.654 \%)$ and book chapters (11, $0.934 \%$ ). Here, proceeding papers belong to articles, and book chapters belong to reviews. So, the articles and reviews were the main document types which were usually statistics such as the citations and the journal impact factor. The citations are always not an indicator of the impact of any research; however, they can indicate the marker of the work in the research community ${ }^{22}$. Higher citations per publication (CPP) were recorded for book chapters $(\mathrm{CPP}=68.18)$ and review articles $(\mathrm{CPP}=43.2)$, compared to research articles $(\mathrm{CPP}=16.38)$ and proceeding papers $(\mathrm{CPP}=36.37)$.

Among the 1319 publications, 1272 (96.437\%) were in English, followed by Japanese $(19 ; 1.44 \%)$, Portuguese (15; 1.137\%), French (9; 0.682\%), Spanish (3;0.277\%) and Hungarian $(1 ; 0.076 \%)$. English was the dominating language in documents from the $\mathrm{WoS}^{22-25}$. Most papers are published in English as SCIE and SSCI mostly consist of English journals and scholars tend to publish their articles in English for wider acceptance.

\section{Publication output and scientific descriptors}

All the publications were assessed by the following aspects: year, publication, country/region, author, organization, citation and $h$-index, average citation per publication, countries per publication, authors per publication, organizations per publication. Table 2 presents the publication output on rice research with mean citations, references and page counts. An absolute growth in rice research is evident. There were more than 10 articles from 1990 and then the publications increased gradually each year; the number was 121 in 2018 (until 5 December 2018). Almost $37.5 \%$ of the articles were published in the last five years of the study period (2014-2018) and $64.3 \%$ of the articles were published in the last ten years (2009-2018). 
Table 2. Scientific output characteristics from 1965 to 2018 (till to 5 December 2018)

\begin{tabular}{|c|c|c|c|c|c|c|c|c|c|c|c|c|}
\hline PY & $\mathrm{TP}$ & Ratio of $1319(\%)$ & $\mathrm{TC}$ & ACPP & $h$-index & $\mathrm{AU}$ & CRT & OT & AU/TP & $\mathrm{CRT} / \mathrm{TP}$ & $\mathrm{OT} / \mathrm{TP}$ & APPP \\
\hline 1965 & 1 & 0.076 & 7 & 7.00 & 1 & 2 & 1 & 1 & 2.00 & 1.00 & 1.00 & 11.00 \\
\hline 1977 & 1 & 0.076 & 1 & 0.00 & 0 & 2 & 1 & 1 & 2.00 & 1.00 & 1.00 & 3.00 \\
\hline 1979 & 2 & 0.152 & 6 & 3.00 & 1 & 4 & 2 & 2 & 2.00 & 1.00 & 1.00 & 11.00 \\
\hline 1981 & 2 & 0.152 & 3 & 1.50 & 1 & 4 & 3 & 4 & 2.00 & 1.50 & 2.00 & 6.50 \\
\hline 1982 & 1 & 0.076 & 0 & 0.00 & 0 & 1 & 1 & 1 & 1.00 & 1.00 & 1.00 & 7.00 \\
\hline 1984 & 1 & 0.076 & 69 & 69.00 & 1 & 2 & 1 & 1 & 2.00 & 1.00 & 1.00 & 6.00 \\
\hline 1985 & 1 & 0.076 & 14 & 14.00 & 1 & 4 & 1 & 1 & 4.00 & 1.00 & 1.00 & 12.00 \\
\hline 1986 & 3 & 0.227 & 49 & 16.33 & 2 & 7 & 3 & 3 & 2.33 & 1.00 & 1.00 & 7.33 \\
\hline 1987 & 5 & 0.379 & 6 & 1.20 & 2 & 12 & 5 & 7 & 2.40 & 1.00 & 1.40 & 7.00 \\
\hline 1989 & 6 & 0.455 & 46 & 7.67 & 3 & 21 & 6 & 9 & 3.50 & 1.00 & 1.50 & 11.67 \\
\hline 1990 & 12 & 0.910 & 116 & 9.67 & 5 & 28 & 13 & 13 & 2.33 & 1.08 & 1.08 & 7.33 \\
\hline 1991 & 17 & 1.289 & 92 & 5.41 & 5 & 52 & 25 & 25 & 3.06 & 1.47 & 1.47 & 7.18 \\
\hline 1992 & 11 & 0.834 & 83 & 7.55 & 4 & 31 & 12 & 13 & 2.82 & 1.09 & 1.18 & 7.45 \\
\hline 1993 & 16 & 1.213 & 122 & 7.63 & 7 & 43 & 18 & 21 & 2.69 & 1.13 & 1.31 & 7.38 \\
\hline 1995 & 11 & 0.834 & 204 & 18.55 & 5 & 37 & 15 & 16 & 3.36 & 1.36 & 1.45 & 6.36 \\
\hline 1996 & 11 & 0.834 & 268 & 24.36 & 7 & 32 & 15 & 16 & 2.91 & 1.36 & 1.45 & 9.73 \\
\hline 1997 & 13 & 0.986 & 537 & 41.31 & 6 & 43 & 15 & 17 & 3.31 & 1.15 & 1.31 & 10.23 \\
\hline 1998 & 13 & 0.986 & 549 & 42.23 & 11 & 57 & 20 & 29 & 4.38 & 1.54 & 2.23 & 12.85 \\
\hline 1999 & 27 & 2.047 & 738 & 27.33 & 14 & 99 & 44 & 53 & 3.67 & 1.63 & 1.96 & 11.22 \\
\hline 2000 & 19 & 1.440 & 691 & 36.37 & 12 & 64 & 34 & 42 & 3.37 & 1.79 & 2.21 & 11.68 \\
\hline 2001 & 21 & 1.592 & 995 & 47.38 & 13 & 68 & 29 & 34 & 3.24 & 1.38 & 1.62 & 11.43 \\
\hline 2002 & 22 & 1.668 & 1157 & 52.59 & 17 & 68 & 37 & 44 & 3.09 & 1.68 & 2.00 & 12.82 \\
\hline 2003 & 24 & 1.820 & 461 & 19.21 & 12 & 74 & 33 & 45 & 3.08 & 1.38 & 1.88 & 10.63 \\
\hline 2004 & 37 & 2.805 & 1503 & 40.62 & 18 & 141 & 58 & 82 & 3.81 & 1.57 & 2.22 & 10.30 \\
\hline 2005 & 35 & 2.654 & 1585 & 45.29 & 19 & 141 & 57 & 79 & 4.03 & 1.63 & 2.26 & 13.54 \\
\hline 2006 & 41 & 3.108 & 1156 & 28.20 & 22 & 161 & 52 & 70 & 3.93 & 1.27 & 1.71 & 11.24 \\
\hline 2007 & 44 & 3.336 & 1588 & 36.09 & 20 & 183 & 79 & 110 & 4.16 & 1.80 & 2.50 & 11.50 \\
\hline 2008 & 53 & 4.018 & 1383 & 26.09 & 19 & 243 & 77 & 103 & 4.58 & 1.45 & 1.94 & 10.21 \\
\hline 2009 & 67 & 5.080 & 1809 & 27.00 & 25 & 282 & 100 & 141 & 4.21 & 1.49 & 2.10 & 11.06 \\
\hline 2012 & 61 & 4.625 & 790 & 12.95 & 16 & 275 & 88 & 130 & 4.51 & 1.44 & 2.13 & 9.95 \\
\hline 2013 & 90 & 6.823 & 1081 & 12.01 & 19 & 443 & 146 & 218 & 4.92 & 1.62 & 2.42 & 11.21 \\
\hline 2014 & 90 & 6.823 & 800 & 8.89 & 16 & 432 & 141 & 207 & 4.80 & 1.57 & 2.30 & 11.69 \\
\hline 2015 & 88 & 6.672 & 844 & 9.59 & 15 & 504 & 163 & 243 & 5.73 & 1.85 & 2.76 & 12.52 \\
\hline 2016 & 90 & 6.823 & 397 & 4.41 & 11 & 436 & 136 & 231 & 4.84 & 1.51 & 2.57 & 11.97 \\
\hline 2017 & 106 & 8.036 & 299 & 2.82 & 7 & 562 & 166 & 261 & 5.30 & 1.57 & 2.46 & 13.31 \\
\hline 2018 & 121 & 9.174 & 42 & 0.35 & 3 & 639 & 175 & 299 & 5.28 & 1.45 & 2.47 & 11.21 \\
\hline 2019 & 6 & 0.455 & 0 & 0.00 & 0 & 31 & 9 & 14 & 5.17 & 1.50 & 2.33 & 9.33 \\
\hline
\end{tabular}

PY, Published year; TP, Total publication; TC, Total citations; ACPP, Average citation per publication (TC/TP); AU, Author number; CRT, Countries/regions occurrence times; OT, Organizations occurrence times; APPP, Average pages per publication.

Figure 1 shows the publication trend and mean citation per paper. The data were collected on 5 December 2018; number of papers in 2018 was over 121 and six papers in 2019 were online. The annual number of publications has increased over the past 30 years, but with some fluctuations. The growth has been an exponential of rice literature $\left(R^{2}=0.93\right)$. The mean citation was not stable and mean citation rate was highest for papers published in 2002.

Considering the data from 1990 to 2018, the mean page counts per year from 7.33 to 11.21 , and the most mean pages per paper is 13.54 in 2005 . There were average 3.90 authors per paper from 2.33 to 5.28 while the most mean authors per article is 5.73 in 2015 , and countries/ regions per article is 1.49 from 1.08 to 1.45 while the most countries/regions per article is 1.85 in 2015, and the organizations per article is 1.98 from 1.08 to 2.47 while the most organizations per article is 2.76 in 2015 , and the increase tendency of organizations per article is faster than that of countries/regions per article (Figure 2). The authorship, countries/regions and organizations per article patterns in rice research indicate towards the multiauthorship and co-operations. All these indicators suggest that there was increase in the research activities on rice in the last decade.

\section{Web of Science categories}

The publications were refined by 'Agronomy' subject categories of WoS. So, the total articles belong to the Agronomy category, and then they are also followed by 
other categories. There are $18 \mathrm{WoS}$ subject categories for irrigation and rice research in the science edition, and Table 3 lists the top 10 categories. Among these, the top five categories include Agronomy (1319 articles; 100\%), Water resources $(374 ; 28.355 \%)$, Agricultural engineering $(166 ; 12.585 \%)$, Plant sciences $(135 ; 10.235 \%)$ and Soil science $(112 ; 8.491 \%)$, each with more than 100 papers. Journals or papers may be classified into two or more categories in WoS. This shows the multidisciplinary character of the research field ${ }^{26}$.

\section{Core journals}

The analysis of journals helps find the most suitable ones to publish relevant studies ${ }^{27}$. All the 1319 papers

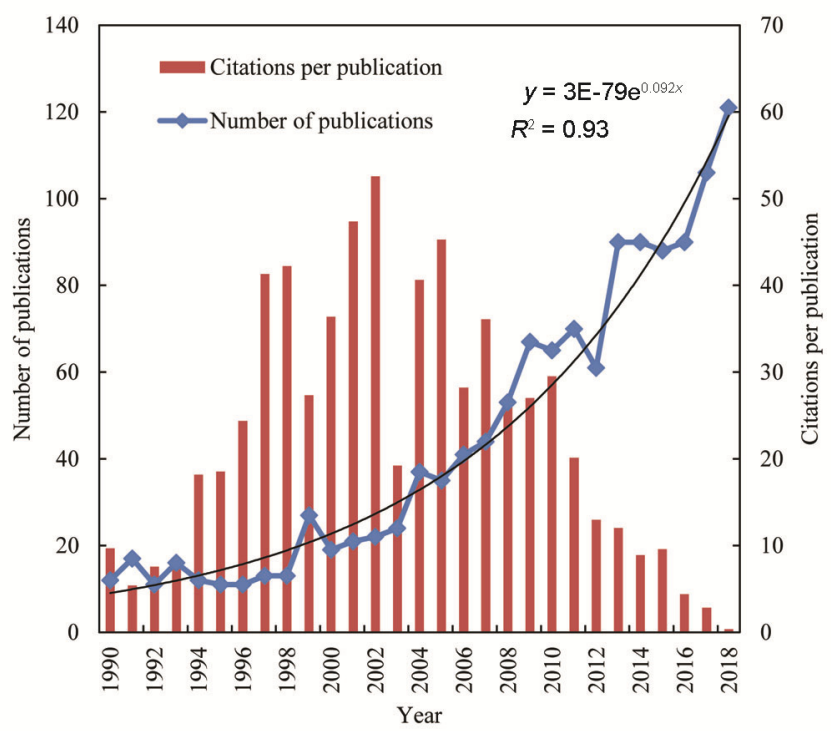

Figure 1. Number of publications with average citations per publication during 1990 to 2018 .

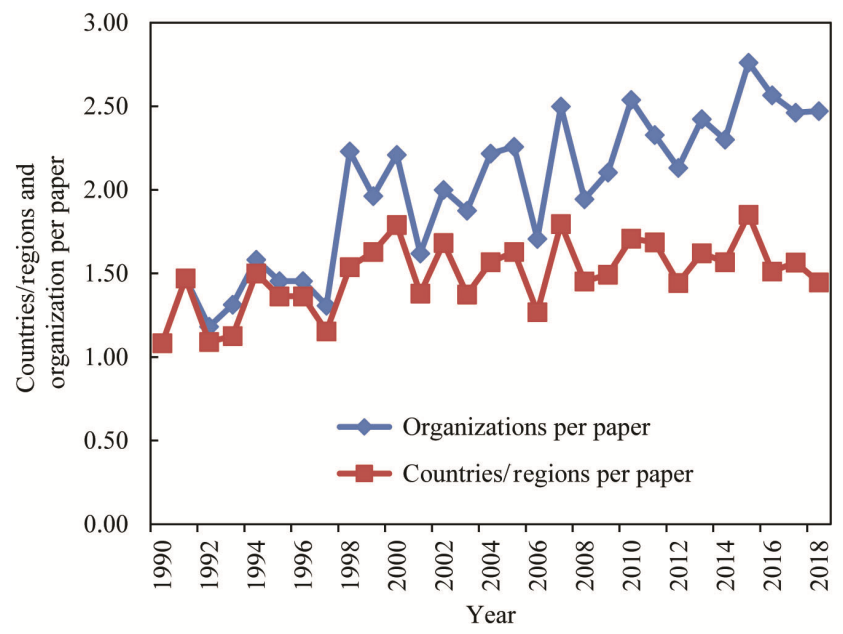

Figure 2. Changes in countries/regions and organizations per publication during 1990 to 2018 . were published in 98 journals and book chapters. The top 13 core journals are shown in Table 4, along with total publications, IF according to JCR 2018, total citations and average citation per paper (ACPP). These 13 journals have published almost $74.9 \%$ of the total 1319 rice research papers. Agricultural Water Management was the most productive journal with 273 articles (20.697\%), followed by Field Crops Research (176; 13.343\%), and Paddy and Water Environment (162; 12.282\%), each with more than 150 papers. Five journals were published from USA, followed by the four from The Netherlands, two from England, and one each from Germany and India. Plant and Soil, European Journal of Agronomy, Agricultural Water Management, and Field Crops Research were for journals with higher IF; Indian Journal of Agronomy does not have an IF. Papers published in Plant and Soil had the highest citations per article (44.69), as four articles were highly cited, i.e. more than 111 times. This indicates that the IFs are based on the few highly cited articles and this may not be true for all the articles published in the journal $^{23}$. Thus, authors can choose the most suitable journal to publish papers related to this research field.

Figure 3 shows the changes of the top five journal publications with each year from 1978 to 2018. The Indian Journal of Agronomy mainly published papers from 1987 to 2005; we only checked IF in 2004. The annual papers of the other four journals increased over the years, especially after the year 2000 .

\section{Publication distribution by authors}

Table 5 reveals that a total of 3832 authors and 5872 frequency times participated in related studies and published 1319 papers. Thus we get 0.344 articles (1319 publications by 3832 authors) per author, and the average number of authors per paper is 4.452 (5872 records of authors for 1319 papers).

The analysed records listed 3832 authors, among whom $2902(75.73 \%)$ had only one publications, 516 $(13.47 \%)$ had two publications, $196(5.11 \%)$ had three

Table 3. Top $10 \mathrm{Web}$ of Science (WoS) categories for irrigation and rice research

\begin{tabular}{clrc}
\hline & & & $\begin{array}{c}\text { Ratio of } \\
\text { Rank }\end{array}$ \\
\hline 1 & Agronomy & TP & $1319(\%)$ \\
2 & Water resources & 1319 & 100 \\
3 & Agricultural engineering & 374 & 28.355 \\
4 & Plant sciences & 166 & 12.585 \\
5 & Soil science & 135 & 10.235 \\
6 & Agriculture multidisciplinary & 112 & 8.491 \\
7 & Chemistry analytical & 41 & 3.108 \\
8 & Meteorology atmospheric sciences & 33 & 2.502 \\
9 & Forestry & 22 & 2.502 \\
10 & Horticulture & 19 & 1.668 \\
\hline
\end{tabular}


Table 4. Top 13 journals indexed using WoS during 1965 to 2018

\begin{tabular}{|c|c|c|c|c|c|c|c|c|}
\hline Rank & Journal & $\mathrm{TP}$ & Ratio of $1319(\%)$ & $\mathrm{TC}$ & $\mathrm{ACPP}$ & $h$-index & IF & Country \\
\hline 1 & Agricultural Water Management & 273 & 20.697 & 7254 & 26.57 & 42 & 3.182 & The Netherlands \\
\hline 2 & Field Crops Research & 176 & 13.343 & 4803 & 27.29 & 39 & 3.127 & The Netherlands \\
\hline 3 & Paddy and Water Environment & 162 & 12.282 & 1385 & 8.56 & 20 & 1.379 & Germany \\
\hline 4 & Irrigation and Drainage & 68 & 5.155 & 341 & 5.01 & 10 & 0.707 & USA \\
\hline 5 & Indian Journal of Agronomy & 44 & 3.336 & 103 & 2.34 & 4 & & India \\
\hline 6 & Plant Production Science & 39 & 2.957 & 881 & 22.59 & 14 & 0.875 & England \\
\hline 7 & Agronomy Journal & 36 & 2.729 & 912 & 25.33 & 15 & 1.897 & USA \\
\hline 8 & Plant and Soil & 36 & 2.729 & 1609 & 44.69 & 20 & 3.306 & The Netherlands \\
\hline 9 & Communications in Soil Science and Plant Analysis & 33 & 2.502 & 292 & 8.85 & 9 & 0.54 & USA \\
\hline 10 & Irrigation Science & 33 & 2.502 & 569 & 17.24 & 15 & 1.653 & USA \\
\hline 11 & Experimental Agriculture & 31 & 2.350 & 309 & 9.97 & 10 & 1.68 & USA \\
\hline 12 & Archives of Agronomy and Soil Science & 29 & 2.199 & 67 & 2.31 & 5 & 2.254 & England \\
\hline 13 & European Journal of Agronomy & 28 & 2.123 & 475 & 16.96 & 14 & 3.192 & The Netherlands \\
\hline
\end{tabular}

IF, Impact factor -2017 .

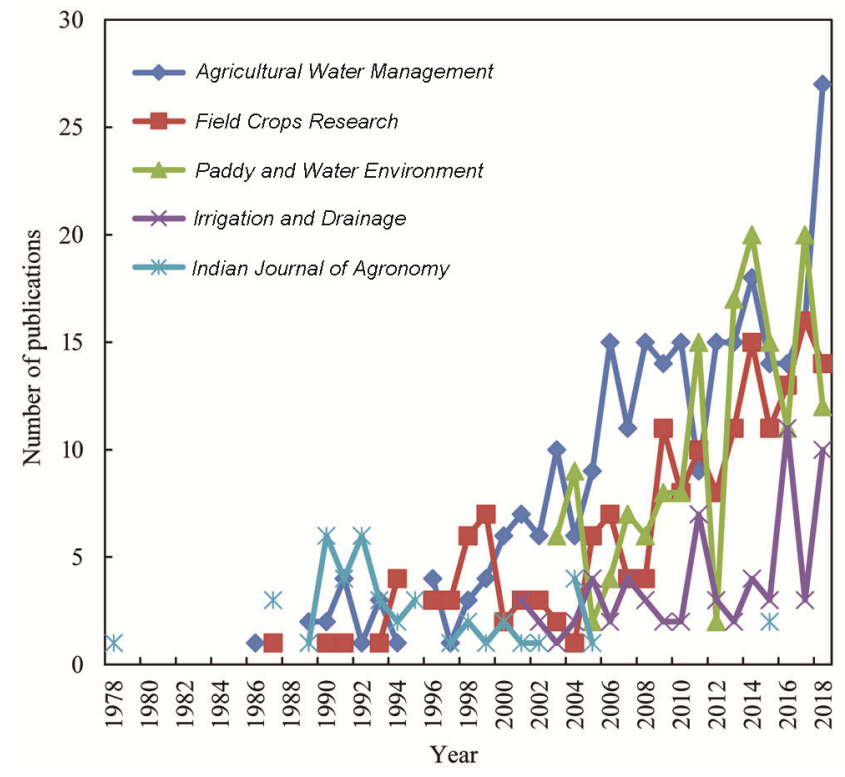

Figure 3. Changes in annual publications during 1978 to 2018.

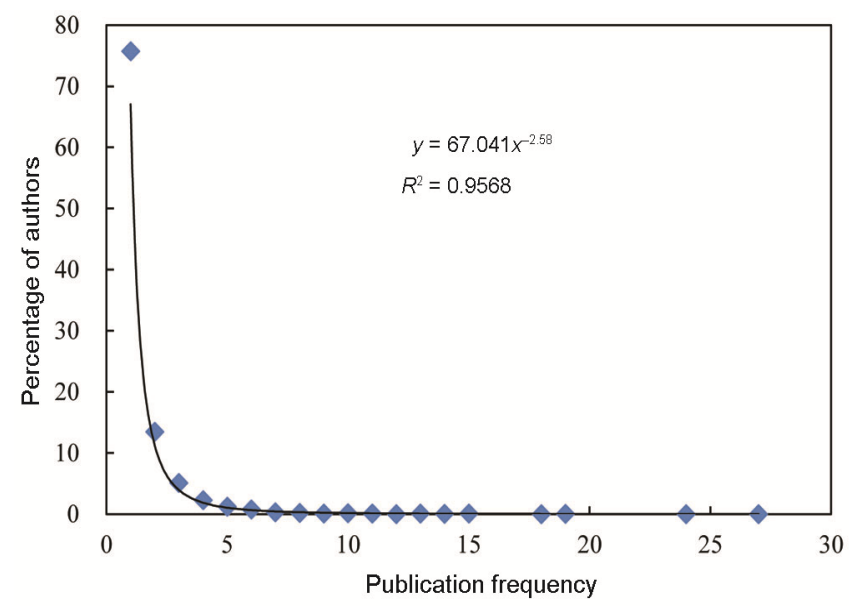

Figure 4. Distribution of number of authors with different frequencies. publications and $88(2.30 \%)$ authors had four publications. A total of $3418(89.20 \%), 3614(94.31 \%)$ and 3702 (96.61\%) authors had $\leq 2,3$ and 4 papers respectively. The relationship between relative frequency of authors and their corresponding publications was adapted to the Lotka's law, an inverse square law, which describes the frequency of publication by authors in any given field; and the result was similar to Mesdaghinia et al. ${ }^{28}$. Table 5 shows the frequencies of authors and the number of publications. Further analysis indicated that the number of authors versus frequency obeys the power-law distribution (Figure 4).

The top 12 most productive authors (more than 14 papers per author) altogether contributed 209 papers, accounting for $15.845 \%$ of 1319 publications. Among these five authors in China were from two organizations, viz. Hohai University (S. Z. Peng, J. Z. Xu and S. H. Yang) and Yangzhou University (J. C. Yang and J. H. Zhang); three (B. A. M. Bouman, E. Humphreys and Sudhir Yadav) were from the International Rice Research Institute (IRRI), Philippines; two (B. S. Chauhan and S. Fukai) were from the University of Queensland, Australia; one (A. Kumar) was from the Indian Council of Agricultural Research (ICAR) and one author (A. R. Sepaskhah) was from Shiraz University, Iran. There are many advantages of measuring scientific output using the $h$-index, which is the most popular single measure of scientific output for both productivity and impact. The top 12 most productive authors not only have more papers, but also have a high $h$-index (Table 6).

\section{Countries/regions}

There were 88 countries contributing to the 1319 publications in this study. Table 7 lists the top 15 most productive countries publishing $117.91 \%$ of all papers (153.91\%). The 1319 papers were analysed by countries or regions and sorted in reverse order by their total number-26 countries had only one paper each, seven 
GENERAL ARTICLES

Table 5. Frequency of authors and publications during 1965 to 2018

\begin{tabular}{ccccccc}
\hline $\begin{array}{l}\text { Frequency of } \\
\text { publications }\end{array}$ & $\begin{array}{c}\text { Number of } \\
\text { authors }\end{array}$ & Percentage & $\begin{array}{c}\text { Number of total } \\
\text { authors }\end{array}$ & Percentage & $\begin{array}{c}\text { Accumulation } \\
\text { of authors }\end{array}$ & Percentage \\
\hline 1 & 2902 & 75.73 & 2902 & 49.42 & 2902 & 49.42 \\
2 & 516 & 13.47 & 1032 & 17.57 & 3934 & 67.00 \\
3 & 196 & 5.11 & 588 & 10.01 & 4522 & 77.01 \\
4 & 88 & 2.30 & 352 & 5.99 & 4874 & 83.00 \\
5 & 47 & 1.23 & 235 & 4.00 & 5109 & 87.01 \\
6 & 29 & 0.76 & 174 & 2.96 & 5283 & 89.97 \\
7 & 12 & 0.31 & 84 & 1.43 & 5367 & 91.40 \\
8 & 9 & 0.23 & 72 & 1.23 & 5439 & 92.63 \\
9 & 5 & 0.13 & 45 & 0.77 & 5484 & 93.39 \\
10 & 6 & 0.16 & 60 & 1.02 & 5544 & 94.41 \\
11 & 5 & 0.13 & 55 & 0.94 & 5599 & 95.35 \\
12 & 1 & 0.03 & 12 & 0.20 & 5611 & 95.56 \\
13 & 4 & 0.10 & 52 & 0.89 & 5663 & 96.44 \\
14 & 3 & 0.08 & 42 & 0.72 & 5705 & 97.16 \\
15 & 4 & 0.10 & 60 & 1.02 & 5765 & 98.18 \\
18 & 1 & 0.03 & 18 & 0.31 & 5783 & 98.48 \\
19 & 2 & 0.05 & 38 & 0.65 & 5821 & 99.13 \\
24 & 1 & 0.03 & 24 & 0.41 & 5845 & 99.54 \\
27 & 1 & 0.03 & 27 & 0.46 & 5872 & 100.00 \\
\hline
\end{tabular}

Table 6. Top 12 authors indexed using WoS

\begin{tabular}{|c|c|c|c|c|c|c|c|c|}
\hline Rank & Authors & Records & Ratio of $1319(\%)$ & Citations & Average citation & $h$-index & Period & Country \\
\hline 1 & E. Humphreys & 27 & 2.05 & 761 & 28.19 & 14 & $2005-2018$ & Philippines \\
\hline 2 & B. A. M. Bouman & 24 & 1.82 & 2555 & 106.46 & 20 & $2001-2015$ & Philippines \\
\hline 4 & J. Z. Xu & 19 & 1.44 & 264 & 13.89 & 8 & 2011-2018 & China \\
\hline 5 & A. Kumar & 18 & 1.37 & 364 & 20.22 & 9 & 2007-2018 & India \\
\hline 6 & A. R. Sepaskhah & 15 & 1.14 & 169 & 11.27 & 7 & 2004-2014 & Iran \\
\hline 7 & J. C. Yang & 15 & 1.14 & 457 & 30.47 & 11 & 2007-2018 & China \\
\hline 8 & S. H. Yang & 15 & 1.14 & 182 & 12.13 & 6 & 2011-2018 & China \\
\hline 9 & J. H. Zhang & 15 & 1.14 & 456 & 30.40 & 11 & $2007-2018$ & China \\
\hline 10 & B. S. Chauhan & 14 & 1.06 & 213 & 15.21 & 8 & 2010-2018 & Australia \\
\hline 11 & S. Z. Peng & 14 & 1.06 & 229 & 16.36 & 8 & 2009-2015 & China \\
\hline 12 & Sudhir Yadav & 14 & 1.06 & 266 & 19.00 & 8 & 2010-2018 & Philippines \\
\hline
\end{tabular}

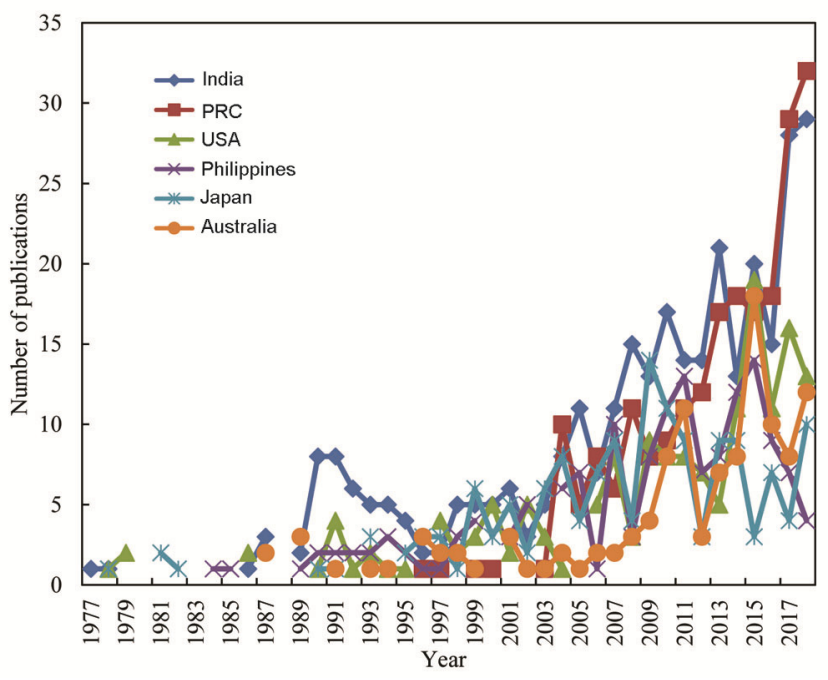

Figure 5. Comparison of growth trends of the top six productive countries during 1977 to 2018 . countries had two papers each, five countries had three papers each, and the remaining 50 countries had from 4 to 313 papers. From 1990 to 2018, the number of mean countries/regions per article is 1.49 from 1.08 to 1.45 , while the average number of the most countries/regions per article is 1.85 in 2015 . The average number of countries/regions per paper was relatively constant, but, it was higher in the last ten years, reflecting more international cooperation.

Table 7 shows the top 15 countries/regions that published more than 35 papers. Of these, the top six countries published more than 121 papers. India was identified as the largest contributor, followed by China. Among the 15 countries/regions, there are nine Asian countries, three European countries, one from Australia, one from North America and one from South America. For the countries/regions, there are more publications, and the higher $h$-index. USA had the highest $h$-index (43) among all the 
Table 7. Top 15 countries/regions publishing articles indexed using WoS

\begin{tabular}{|c|c|c|c|c|c|c|c|}
\hline Rank & Country/regions & Records & Ratio (\%) of 1319 & Citations & Average citation & $h$-index & Continent \\
\hline 1 & India & 313 & 23.73 & 5313 & 16.97 & 40 & Asia \\
\hline 2 & China & 218 & 16.53 & 5089 & 23.34 & 38 & Asia \\
\hline 4 & Philippines & 154 & 11.68 & 5982 & 38.84 & 44 & Asia \\
\hline 5 & Japan & 152 & 11.52 & 2249 & 14.8 & 25 & Asia \\
\hline 6 & Australia & 121 & 9.17 & 2358 & 19.49 & 25 & Australia \\
\hline 8 & Germany & 53 & 4.02 & 1299 & 24.51 & 19 & Europe \\
\hline 9 & The Netherlands & 53 & 4.02 & 1975 & 37.26 & 22 & Europe \\
\hline 10 & Brazil & 49 & 3.72 & 277 & 5.65 & 7 & South America \\
\hline 11 & France & 49 & 3.72 & 746 & 15.22 & 14 & Europe \\
\hline 12 & Pakistan & 48 & 3.64 & 737 & 15.35 & 14 & Asia \\
\hline 13 & Iran & 46 & 3.49 & 221 & 4.8 & 8 & Asia \\
\hline 14 & South Korea & 46 & 3.49 & 499 & 10.85 & 14 & Asia \\
\hline 15 & Thailand & 35 & 2.65 & 708 & 20.23 & 13 & Asia \\
\hline
\end{tabular}

Table 8. Top 13 organizations indexed using WoS

\begin{tabular}{|c|c|c|c|c|c|c|c|}
\hline Rank & Organization & Records & Ratio (\%) & Citations & Average citation & $h$-index & Country \\
\hline 1 & Int Rice Res Inst & 122 & 9.25 & 5355 & 43.89 & 39 & Philippines \\
\hline 2 & Punjab Agr Univ & 63 & 4.78 & 1155 & 18.33 & 22 & Pakistan \\
\hline 4 & Univ Queensland & 34 & 2.58 & 832 & 24.47 & 13 & Australia \\
\hline 5 & Univ Agr Faisalabad & 31 & 2.35 & 446 & 14.39 & 11 & Pakistan \\
\hline 6 & Univ Tokyo & 31 & 2.35 & 541 & 17.45 & 13 & Japan \\
\hline 7 & Hohai Univ & 29 & 2.20 & 352 & 12.14 & 11 & China \\
\hline 8 & Indian Agr Res Inst & 29 & 2.20 & 558 & 19.24 & 13 & India \\
\hline 9 & IRRI & 26 & 1.97 & 702 & 27 & 12 & Philippines \\
\hline 10 & Wuhan Univ & 26 & 1.97 & 444 & 17.08 & 11 & China \\
\hline 11 & China Agr Univ & 25 & 1.90 & 653 & 26.12 & 15 & China \\
\hline 12 & CIMMYT & 20 & 1.52 & 812 & 40.6 & 14 & Mexico \\
\hline 13 & Indian Inst Technol & 20 & 1.52 & 489 & 24.45 & 10 & India \\
\hline
\end{tabular}

countries, followed by China (41), Spain (37), Australia (36) and India (33).

Comparison of growth trends shows the top five countries which have published $1121(84.99 \%)$ of the total 1319 articles (153.91\%) (Figure 5). China, second in the list ranked by total articles, has published $218(16.53 \%)$ articles with the fastest growing trend; after the year 2003 the number has increased sharply to 32 by 2018 . This could be due to a series of positive policies that propelled scientific research in China. China has witnessed a sustained increase in scientific research. It ranks second in the world with regard to scientific publications since 2006, particularly taking the leading position in specific fields ${ }^{29}$. The past decades have witnessed a rapid rise of economic development in China, with annual growth rate of a gross domestic product (GDP) is averaging about $10 \%$ since 2000 . In 2010, China overtook Japan as the second largest economy in the world ${ }^{30}$.

\section{Organizations and institutions}

We measured the trends of major contributing organizations, analysing whether certain organizations of interest were increasing or decreasing in significance ${ }^{31}$. Regarding affiliations of authors appearing in the database, 1220 different organizations from academia, government and industry have been identified from a total of 2936 records of organizations. Among them, 829 organizations have only one paper each, 161 organizations have only two papers each, 81 organizations have three papers each, 38 organizations have four papers each and 26 organizations have five papers each.

In addition, there are $37.30 \%$ of articles (total $222.68 \%$ ) produced by the top 13 most productive institutions that published more than 20 papers (Table 8). Among these organizations, four are in China, whereas India, Pakistan and the Philippines each have two, and Australia, Japan and Mexico each have one. In fact, Int Rice Res Inst and IRRI in Table 8 are the same organizations in the Philippines.

China had a high growth rate of publications with the Chinese Academy of Sciences playing a leading role in the country's research output. The Chinese Academy of Sciences was the most productive institute with total articles (36) and contributed $16.5 \%$ of papers from China (218). Hohai University (29), Wuhan University (26) and 
China Agricultural University (25) were among the top 13 organizations. Yangzhou University (17), Zhejiang University (16), Chinese Academy of Agricultural Sciences (14), Nanjing Agricultural University (14), Huazhong Agricultural University (12), University of Chinese Academy of Sciences (11), and Chinese University of Hong Kong (10), have published more than ten articles and reviews more in the agronomy field of rice and irrigation.

\section{The most frequently cited articles}

The total citation count was obtained from SCIE, which shows the total number of times a particular article has been cited by journals listed in the SCI database. Although many articles have been published, a relatively small number of individuals account for a large proportion of citations within the period. Six most frequently cited articles have been cited more than 232 times since their initial publication till 5 December 2018; the total citations for these six papers were 470, 378, 343, 288, 254 and 232 respectively, and the average citation per year was $26.11,25.2,15.59,19.2,18.14$ and 25.78 respectively (Figure 6). The annual citations of the six articles showed an increasing trend during their citation history after the published year, that is, over the cited half-life about 5-6 years based on JCR 2018. The time dependence of a single paper is called its history. In the beginning year (zero year here), this was lower because all papers appeared in that published year.

\section{Conclusions}

We analysed 1319 research articles published on rice and irrigation from the 'Agronomy' category based on WoS for the period 1965-2018. We observed that the number of publications has grown rapidly over the past years; and

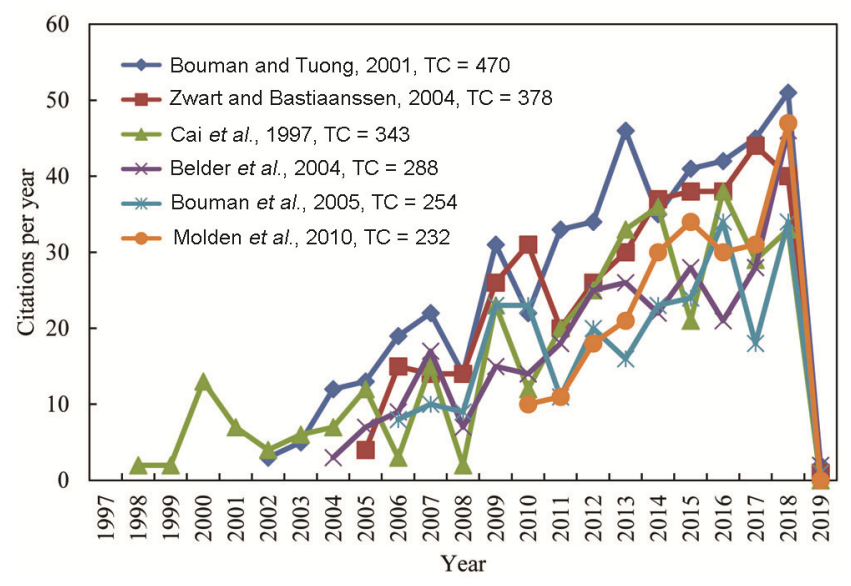

Figure 6. Comparison of citations of the top six articles from their initial publications to 5 December 2018.
English was the dominating language (96.437\%). The top five most productive authors were E. Humphreys (Philippines), B. A. M. Bouman (Philippines), S. Fukai (Australia), J. Z. Xu (China) and A. Kumar (India). There were 98 core journals involved in publication and Agricultural Water Management was the most productive journal with 273 articles (20.697\%), followed by Field Crops Research $(176 ; 13.343 \%)$, and Paddy and Water Environment $(162 ; 12.282 \%)$, each with more than 150 papers. India was the most productive country with 313 articles $(23.73 \%)$, followed by China $(218,16.53 \%)$, USA (163, 12.36\%), Philippines (154, 11.68\%), Japan (152, $11.52 \%$ ) and Australia (121, 9.17\%). Among the institutions working on rice and irrigation, the top three were IRRI, Philippines, Punjab Agricultural University from Pakistan and Chinese Academy of Sciences from China.

Conflicts of interest: The authors declare no conflict of interest.

1. The State of the World's Land and Water Resources for Food and Agriculture Managing Systems at Risk. FAO, Rome and Earthscan, London, 2011.

2. Seck, P. A., Diagne, A., Mohanty, S. and Wopereis, M. C., Crops that feed the world 7: rice. Food Security, 2012, 4, 7-24.

3. Sandhu, N. and Kumar, A., Bridging the rice yield gaps under drought: QTLs, genes, and their use in breeding programs. Agronomy, 2017, 7, 27.

4. Lampayan, R. M., Rejesus, R. M., Singleton, G. R. and Bouman, B. A. M., Adoption and economics of alternate wetting and drying water management for irrigated lowland rice. Field Crops Res., 2015, 170, 95-108.

5. Nguyen, H. T., Fischer, K. S. and Fukai, S., Physiological responses to various water saving systems in rice. Field Crops Res., 2009, 112, 189-198.

6. Varma, P., The system of rice intensification (SRI). In Rice Productivity and Food Security in India, Springer, Singapore, 2017.

7. Varma, P., Adoption of system of rice intensification under information constraints: an analysis for India. J. Dev. Stud., 2018, 54(10), 1838-1857.

8. Doni, F., Mispan, M. S., Suhaimi, N. S. M., Ishak, N. and Uphoff, N., Roles of microbes in supporting sustainable rice production using the system of rice intensification. Appl. Microbiol. Biotechnol., 2019, 103, 5131-5142.

9. Shamshiri, R. R., Ibrahim, B., Balasundram, S. K., Taheri, S. and Weltzien, C., Evaluating system of rice intensification using a modified transplanter: a smart farming solution toward sustainability of paddy fields in Malaysia. Int. J. Agric. Biol. Eng., 2019, 12(2), 54-67.

10. Nie, L. X., Peng, S. B., Chen, M. X., Shah, F., Huang, J. L., Cui, K. H. and Xiang, J., Aerobic rice for water-saving agriculture. A review. Agron. Sustain. Dev., 2012, 32, 411-418.

11. Massey, J. H., Walker, T. W., Anders, M. M., Smith, M. C. and Avila, L. A., Farmer adaptation of intermittent flooding using multiple-inlet rice irrigation in Mississippi. Agric. Water Manage., 2014, 146, 297-304.

12. Price, A. H. et al., Alternate wetting and drying irrigation for rice in Bangladesh: is it sustainable and has plant breeding something to offer? Food Energy Secur., 2013, 2(2), 120-129.

13. Rejesus, R. M., Palis, F. G., Rodriguez, D. G. P., Lampayan, R. M. and Bouman, B. A. M., Impact of the alternate wetting and drying (AWD) water-saving irrigation technique: evidence from 
rice producers in the Philippines. Food Policy, 2011, 36, 280288.

14. Luo, L. J., Breeding for water-saving and drought-resistance rice (WDR) in China. J. Exp. Bot., 2010, 61(13), 3509-3517.

15. Wang, W. Q., Peng, S. B., Liu, H. Y., Tao, Y., Huang, J. L., Cui, K. H. and Nie, L. X., The possibility of replacing puddled transplanted flooded rice with dry seeded rice in central China: a review. Field Crops Res., 2017, 214, 310-320.

16. Velasco-Muñoz, J. F., Aznar-Sánchez, J. A., Belmonte-Ureña, L. J. and López-Serrano, M. J., Advances in water use efficiency in agriculture: a bibliometric analysis. Water, 2018, 10, 377.

17. $\mathrm{Hu}, \mathrm{C} . \mathrm{X}$. and Cao, L. Z., Bibliometric and visual analysis of planthopper research between 1980 and 2017. Curr. Sci., 2018, 114(12), 2445-2452.

18. Peng, S. B., Booming research on rice physiology and management in China: a bibliometric analysis based on three major agronomic journals. J. Integr. Agric., 2017, 16(12), 2726-2735.

19. Zhang, Y., Huang, K., Yu, Y. J. and Yang, B. B., Mapping of water footprint research: a bibliometric analysis during 20062015. J. Clean. Prod., 2017, 149, 70-79.

20. Maassen, S., Bibliometric analysis of research on wastewater irrigation during 1991-2014. Irrig. Drain., 2016, 65, 644-653.

21. Mao, G. Z., Huang, N., Chen, L. and Wang, H. M., Research on biomass energy and environment from the past to the future: a bibliometric analysis. Sci. Total Environ., 2018, 635, 1081-1090.

22. Kolle, S. R. and Shankarappa, T. H., Publication trends in foodborne disease research (1991-2015): a web of science core collection based analysis. J. Agric. Food Inf., 2017, 18, 53-63.

23. Kolle, S. R., Shankarappa, T. H. and Manjunatha, R. T. B., Trends in mango research as seen through Science Citation Expanded Index of Web of Science. Erwerbs-Obstbau, 2018, 60, 261-270.

24. Cañas-Guerrero, I., Mazarrón, F. R., Pou-Merina, A., CallejaPerucho, C. and Díaz-Rubio, G., Bibliometric analysis of research activity in the 'Agronomy' category from the Web of Science, 1997-2011. Eur. J. Agron., 2013, 50, 19-28.
25. Mo, Z. W., Fu, H. Z. and Ho, Y. S., Global development and trend of wind tunnel research from 1991 to 2014: a bibliometric analysis. Environ. Sci. Pollut. Res., 2018, 25, 30257-30270.

26. Elango, B. and Ho, Y. S., Top-cited articles in the field of tribology: a bibliometric analysis. COLLNET J. Scientometr. Inf. Manage., 2018, 12(2), 289-307.

27. Zhao, X., Wang, S. Q. and Wang, X. Y., Characteristics and trends of research on new energy vehicle reliability based on the Web of Science. Sustainability, 2018, 10, 3560.

28. Mesdaghinia, A., Younesian, M., Nasseri, S., Nodehi, R. N. and Hadi, M., Analysis of the microbial risk assessment studies from 1973 to 2015: a bibliometric case study. Scientometrics, 2015, 105(1), 691-707.

29. Fu, H. Z., Chuang, K. Y., Wang, M. H. and Ho, Y. S., Characteristics of research in China assessed with Essential Science Indicators. Scientometrics, 2011, 88(3), 841-862.

30. Liu, W. S., Tang, L., Gu, M. D. and Hu, G. Y., Feature report on China: a bibliometric analysis of China-related articles. Scientometrics, 2015, 102(1), 503-517.

31. Li John, T., What we learn from the shifts in highly cited data from 2001 to 2014? Scientometrics, 2016, 108(1), 57-82.

ACKNOWLEDGEMENTS. This study was funded by The State Key Special Program of High-yield, High-efficient and Low-cost Technology Research and Model Construction of High Effective Utilization of Annual Light and Temperature, and Accurate Control of Water and Fertilizer in Single and Double Season Rice Mixed Area in North Middle and Lower Reaches of the Yangtze River, grant number 2017YFD0301400, PRC.

Received 26 December 2018; revised accepted 3 February 2020

doi: $10.18520 / \mathrm{cs} / \mathrm{v} 119 / \mathrm{i} 3 / 438-446$ 